Produto \& Produção, vol. 12, n. 3, p. 29-37, out. 2011

\title{
Modelagem na contratação de projetos utilizando os conceitos de BPM - gerenciamento de processos de negócio
}

\author{
Claudio Alcides Jacoski \\ Universidade Comunitária de Chapecó - UNOCHAPECO \\ claudio@unochapeco.edu.br \\ Tiago Grzebieluchas \\ Universidade Comunitária de Chapecó - UNOCHAPECO \\ gebe@unochapeco.edu.br
}

\section{RESUMO}

As organizações estão atualmente inseridas em um constante processo de mudança, abandonando velhas teorias e trazendo a tona novos conceitos e realidades. Para que as empresas possam se adaptar as mudanças de mercado e permanecer competitivas, é necessário um processo de reestruturação, buscando se adaptar a novos modelos administrativos. Considerando a atual fase das pequenas e médias empresas da construção civil, em que grande parte dos processos apresenta deficiências no gerenciamento, torna-se de extrema importância adotar um modelo de gestão de processos, para o aumento da competitividade e melhoria continua. A modelagem de processos garante a visualização completa do processo facilitando a percepção de pontos críticos. Foi testada a modelagem de processos para uma incorporadora na contratação dos projetos de arquitetura e de engenharia. Foram utilizados os conceitos de gerenciamento de processos de negócios (BPM), como uma ferramenta para a identificação, assimilação e coerência no fluxo das etapas do processo de gestão de projetos contratados. Pode-se constatar a efetividade da ferramenta BPM, com a apresentação de duas novas opções de processo de contratação e gestão do projeto. Trata-se de uma contribuição significativa, pois apresenta o BPM como uma nova técnica para ser utilizada na modelagem de processos de gestão do projeto.

Palavras-chave: Gerenciamento de processos, Construção civil, BPM, Modelagem de processos.

\begin{abstract}
Organizations are currently placed in a constant process of change, abandoning old theories and using new concepts and realities. Companies should adapt to market changes and remain competitive, requiring a restructuring process, trying to adapt to new administrative models. Considering the current stage of small and medium enterprises in the construction industry, where most cases had weaknesses in management, it is extremely important to adopt a model of case management, to increase the competitiveness and continuous improvement. The modeling of processes ensures the full view of the process, facilitating the perception of critical points. We tested the modeling of processes for engaging the projects incorporated in the architecture and engineering. We used the concepts of business process management (BPM) as an administrative tool and modeling processes to identify, assimilate and consistency in the work flow of the project management contract. It was the effectiveness of BPM tool, with the presentation of two new options for process of hiring and managing the project. This is a significant contribution because it displays the BPM as a new technique to be used for modeling of project processes in civil construction.
\end{abstract}

Keywords: Management processes, Construction, BPM, Modeling processes.

\section{Introdução}

A modelagem de processos constitui-se em uma série de etapas que visam atender os resultados desejados, considerando todas as fases com suas atividades, elevando a compreensão do processo como um todo e aumentando a satisfação do cliente interno. Considerando que em uma organização há um grande número de processos que interagem dentro de vários departamentos, temse então a possibilidade da criação de um sistema de gerenciamento de processos, migrando de uma empresa com visão departamental para uma empresa com visão em processos.

A proposta da utilização do BPM $^{1}$ (Gerenciamento de Processos de Negócios) vai ao encontro da tendência mundial de gerenciamento de processos, em que grandes empresas utilizam estes conceitos como diferencial. O BPM, juntamente com diversas outras ferramentas, como sistemas de gestão da qualidade, Six Sigma, ciclo 
PDCA, entre outros, consituem-se em uma forma de gerenciar processos.

Sempre que exista a possibilidade de identificar processos com algum desperdício, sejam eles referentes a custos, tempo, material ou até mesmo ao não comprimento de prazos, pode-se fazer uso da modelagem.

A primeira etapa de uma modelagem é a modelagem do processo atual (as is). Nesta fase, busca-se conhecer o processo adotado pela empresa, é de extrema importância recolher o maior número possível de informações referentes ao processo, levando em conta a cultura da empresa e as limitações dos agentes do processo. Tendo em mãos o processo utilizado na organização, deve se realizar um estudo contemplando as melhores formas de executá-lo.

É de extrema importância a identificação dos pontos críticos, os quais devem ser primeiramente analisados para que soluções sejam propostas. A última etapa da modelagem é o desenho do processo otimizado (to be), este é o processo a ser implantado na empresa.

A modelagem tem o objetivo de delimitar o processo, identificar suas entradas, saídas, recursos e responsáveis pela sua execução. Assim, tem-se então o mapeamento das atividades, facilitando a sua visualização e conseqüentemente, pode-se reestruturá-las, identificar os pontos críticos, promovendo melhorias.

O BPM contribui para a resolução de problemas e gera soluções para os fluxos. Sua utilização para o controle da complexidade nos processos de empresas faz dele uma ferramenta de fundamental importância, podendo ser usado por grandes corporações a pequenos empreendimentos.

Sob este aspecto é que se experimenta a técnica de BPM em uma incorporadora, avaliando a gestão dos projetos contratados.

\section{Gerenciamento de Processos}

\subsection{Modelagem de processos}

Benedete (2007) destaca que no início da implantação de um gerenciamento de processos de negócios o primeiro passo é dado pela modelagem dos processos. Fase esta que é fundamental para o bom desenvolvimento da otimização e de todas as etapas subseqüentes à modelagem. O autor salienta que um dos maiores erros é não estudar o processo atual detalhadamente, conhecendo-o inteiramente do inicio até sua fase final.

A Etapa de Preparação da Modelagem tem como objetivo obter os subsídios necessários ao processo de modelagem. A primeira atividade consiste na coleta dos documentos que regulamentam os processos e todos os artefatos gerados na etapa anterior. A partir disso, é possível ter uma visão geral do negócio da empresa e com isso identificar os processos que devem ser modelados e quais pessoas devem ser alocadas para auxiliar a modelagem, estipulando funções para cada uma delas. (CRUZ et al. 2006, p. 12).

Conforme Back et al. (1998), para que a organização possa implementar uma modelagem adequada, além de ferramentas, metodologias e técnicas apropriadas ao processo é imprescindível conhecê-lo detalhadamente. Sendo assim, é necessário modelar o processo para ter uma visão global do mesmo.

Para Cruz (2006), a seleção dos funcionários que integrarão a equipe de modelagem é uma fase extremamente significante, pois o resultado da modelagem é diretamente influenciado pela competência teórica ou prática daqueles que executam as atividades. Nesta etapa devem ser coletadas informações relativas a cada um dos integrantes, onde podem ser aplicados questionários ou entrevistas. Assim, é possível compreender o grau de conhecimento necessário para a execução de cada atividade.

\subsection{BPM -(Business Processes Management)}

Um processo de negócio segundo Macedo e Schimitz (2001), pode ser definido como um conjunto de atividades estruturadas destinadas a resultar num produto especificado para um determinado cliente ou mercado. Os processos apresentam custo, prazos, qualidade de produção e satisfação do cliente. Para melhorar o processo, devem-se reduzir os custos e, junto a isso, aumentar a satisfação do cliente.

A NBR ISO 9001 descreve que para uma empresa trabalhar de maneira dinâmica e eficiente, a mesma deve identificar e coordenar diversas atividades interligadas. "Uma atividade que usa recursos e que é gerenciada de forma a possibilitar transformação de entradas em saídas pode ser considerada componente de um processo." O que ocorre muitas vezes é que a entrada de um processo é à saída do processo anterior. A norma considera como sendo uma abordagem de processo, a implantação de um sistema de processos em que deve se realizar a identificação, integração e o gerenciamento dos processos. Tendo como vantagem desta abordagem o controle individual e contínuo dos processos dentro do sistema, bem como uma melhor interação e combinação entre os mesmos.

Conforme Baldam et al (2007), nas organizações além dos processos a modelar, é comum que ocorram processos esporádicos, imprescindíveis e com características tão particulares, que é desnecessário a adoção de uma modelagem.

Ao se implementar um processo que raramente é executado, pode ocorrer um conflito em sua caracterização, pois o mesmo pode ser executado com técnicas típicas de gerenciamento de projetos. Baldam et al. (2007), exemplifica: "um planejamento anual de visitas a instalações é uma tarefa realizada todo ano, logo é um processo. Não caracteriza resultado único, o que implicaria em um projeto. Mas sua execução pode não justificar uma automação, pois é rara." O autor define 
este como sendo um típico caso de fronteira, pois há uma mistura de conceitos.

"Os processos têm elementos como custo, prazos, qualidade de produção e satisfação do cliente. Quando se reduz os custos ou se aumenta a satisfação do cliente, melhora-se o processo em si. A adoção de uma abordagem de processo significa a adoção do ponto de vista do cliente. Os processos são a estrutura pela qual uma organização faz o necessário para produzir valor para seus clientes. Em conseqüência, uma importante medida do processo é a satisfação do cliente com o produto" (MACEDO; SCHIMITZ, 2001, p. 3)

"Uma orientação para processos ajuda a representar e compreender como a organização funciona, revelando estrangulamentos, ambigüidades, redundâncias e outros problemas. Compreendendo como os processos de fato são executados, torna-se possível otimizá-los de forma que a organização possa vir a funcionar melhor. Desta forma, pode-se obter a redução de tempos de ciclo, a diminuição de custos e a melhoria da eficiência e da qualidade." (CAVALCANTI et al. 2006, p. 2).

Segundo Cruz (2006), os processos variam dentro das empresas em decorrência de inúmeras diferenças: pessoas, atividades de negócios, instruções de diferentes gestores e fornecedores. Com isso, eleva-se a variação de entradas gerando também uma variação das saídas.

Conforme Baldam et al. (2007), alguns autores apontam o BPM como uma ferramenta e não técnica gerencial. Assim o enfoque é dado ao gerenciamento de "processos de negócios (business process), expressão que recupera o sentido latino do termo negócio, que não se restringe ao seu uso corrente hoje com trato mercantil (negotium, 'ocupação, trabalho')'.

Para Benedete (2007, p.13) "a Gestão de Processos de Negócios (BPM) visa mapear e melhorar os processos de negócio da empresa, através de uma abordagem baseada em um ciclo de vida de modelagem, desenvolvimento, execução, monitoração, análise e otimização dos processos de negócio [...], visto como uma disciplina de gestão é a habilidade de continuamente otimizar aqueles processos operacionais que são mais diretamente relacionados à obtenção dos objetivos da corporação". Para representar o ciclo do BPM, apresenta-se a figura abaixo:

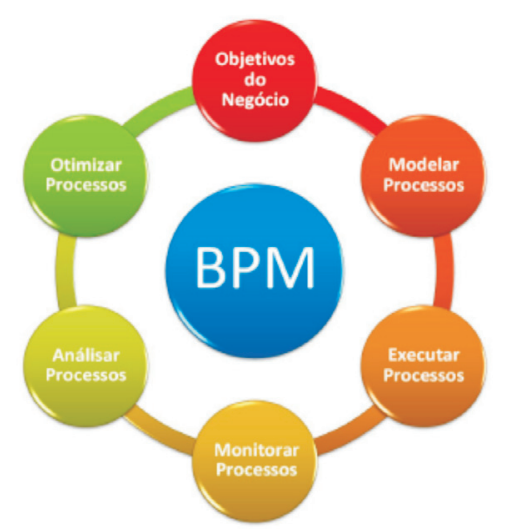

Figura 1 - Ciclo do BPM. Fonte: Benedete (2007)
Uma organização é composta por um conjunto de processos, que são as atividades de negócio executadas com o objetivo de agregar valor, realizar os desejos de seus clientes e criar rendimento. Identificar e mapear os processos internos é uma atitude que permite que a empresa se torne mais competitiva, otimizando o tempo e alcançando melhores resultados. (CRUZ et al. 2006, p10).

Conforme Benedete (2007), ao se implantar o BPM e ao apresentarem melhorias, deve ser iniciado um planejamento para uma adoção mais abrangente, para que aos poucos a organização com a visão orientada a funções ou departamental torne-se uma empresa voltada a processos com uma visão corporativa.

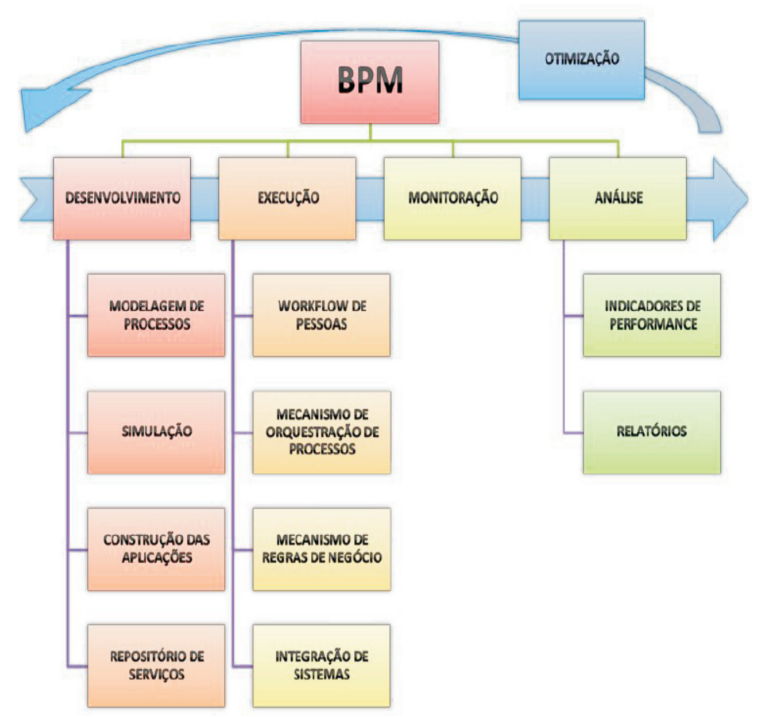

Figura 2 - Ciclo de vida e componentes de uma solução BPM. Fonte: (BENEDETE 2007, p23)

Conforme Baldam et al. (2007), é a modelagem a fase mais perceptível do BPM, onde cada autor apresenta uma determinada técnica ou metodologia de otimização, obtendo uma grande variedade de opções para aplicação, deve-se então identificar aquela que mais se adapte ao processo em estudo. São dois modelos possíveis para modelar. O primeiro refere-se à modelagem do processo atual representada como "As Is" e a segunda como "To $B e$ ", que se entende como a otimização e modelagem do estado almejado.

A composição destes dois modelos de processos de negócio ( $A S$ - $I S$ e $T O-B E$ ) é a mesma, porém seus níveis de detalhamento podem ser diferentes. É comum, que uma primeira abordagem aplicada a um macroprocesso, que será foco de adequações e melhorias, seja mais sucinta, ou seja, que possua o mínimo necessário ao entendimento dos profissionais envolvidos, servir de base para a implantação das melhorias. [..] são obtidos os modelos de processos de negócio finais do projeto (TO-BE), contendo a visão atualizada, além do nível de detalhamento adequado. Este novo produto $(T O-B E)$ deverá ser utilizado futuramente como base, tornando se um $A S-I S$ para o próximo projeto. (CAVALCANTI et al. 2007, p. 3). 


\subsection{Gestão do processo de projeto}

"As características básicas do processo de produção da construção civil são definidas a partir das características do produto estabelecidas no projeto. A qualidade do projeto para o executor de obras estará diretamente relacionada à sua capacidade de proporcionar elevada produtividade do processo de execução dos empreendimentos projetados". (SILVA; SOUZA, 2003, p. 24).

Souza e Melhado (2003) definem como sendo a equipe de projeto um grupo constituído de agentes responsáveis por idealizar arquitetônica, técnica e economicamente o empreendimento, sendo assim, participam desta equipe, arquitetos, engenheiros-projetistas, consultores, economistas, controlador técnico e coordenador de segurança. $\mathrm{O}$ autor salienta ainda que o arquiteto é normalmente o coordenador de projetos.

"A equipe formada pelos profissionais de coordenação e desenvolvimento dos projetos é co-responsável por planejar o processo de elaboração de projetos para cada obra, identificando as etapas e considerando as diferentes técnicas necessárias, de acordo com a especificidade do empreendimento. Por sua vez, o planejamento do processo de projeto é de responsabilidade do coordenador de projetos." (AMARAL, 2006, p. 1421).

"Para a integração dos projetos e produção, a primeira questão que se coloca é a necessidade de coordenação entre os vários projetos de produtos e do processo, que devem ser desenvolvidos em conjunto, buscando a otimização global das características dos edifícios." (BRAGAGLIA, 2006, p. 48).

Para Coradi (2004), o projetista dimensiona de maneira focada, baseado no dimensionamento conceitual da arquitetura, gerando assim interferência com o dimensionamento da estrutura. Desta maneira, cria-se a necessidade de compatibilização, em que o sujeito responsável deve compreender o raciocínio conceitual e levar as informações para discussão.

Ao se avaliar a gestão do projeto em empresas incorporadoras, pode-se aproveitar todo o conjunto de conhecimento sobre a gestão do processo do projeto, embora neste caso avalia-se a gestão da contratação e do contrato do projeto do empreendimento.

\section{Desenvolvimento da Modelagem em uma Incorporadora}

\subsection{Etapas metodológicas}

a) a primeira etapa consistiu-se na identificação das tarefas do processo atual através de uma entrevista não estruturada. b) na segunda etapa a modelagem do processo atual da gestão de projeto (as is) e da comparação deste modelo com as boas práticas descritas na bibliografia;

c) na terceira etapa foram definidas e priorizadas soluções para os problemas atuais;

d) na quarta foram modeladas duas sugestões de processo otimizado (to be).

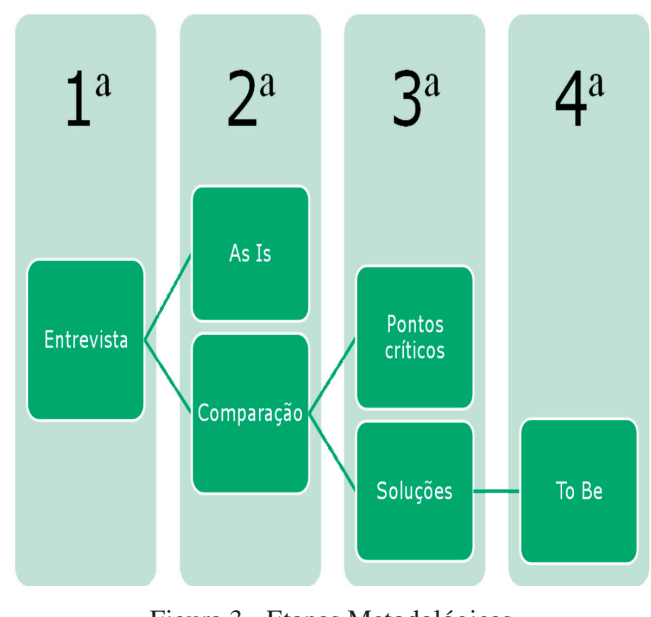

\subsection{Estudo de caso}

Trata-se de uma empresa do ramo de incorporação estabelecida no oeste de Santa Catarina, com implementação de um sistema de gestão de qualidade que atende os requisitos da norma NBR ISO 9001:2000, desde o ano de 2006. A empresa emprega cerca de 120 funcionários. Com o foco na incorporação a empresa tem como escopo: incorporação, construção e venda de imóveis residenciais e comerciais.

Como a empresa mantém um sistema de gestão da qualidade a identificação dos processos e suas aplicações por toda a organização ficou facilitada, principalmente pela cultura do registro dos processos já existir. Determinouse a seqüência e interação desses processos, buscando definir critérios e métodos necessários para assegurar que a operação e controle.

\section{Modelagem do Processo da Gestão do Projeto}

Na figura 4 é possível avaliar o processo de gestão do projeto conforme é executado atualmente (as is), colhido durante a pesquisa com os agentes que participam do processo. Foi utilizada a ferramenta "BizAgi Xpress Edition" para a produção da modelagem dos processos.

Na figura 5 e 6, trata-se de oferecer duas opções para a otimização do processo atual e chama-se atenção que foram produzidas soluções otimizadas que visam a melhoria da produtividade obtida no desenvolvimento do processo. 
Jacoski, C. A.; Grzebieluchas, T. - Modelagem na contratação de projetos utilizando os conceitos de BPM...

\subsection{Resultado da modelagem realizada}

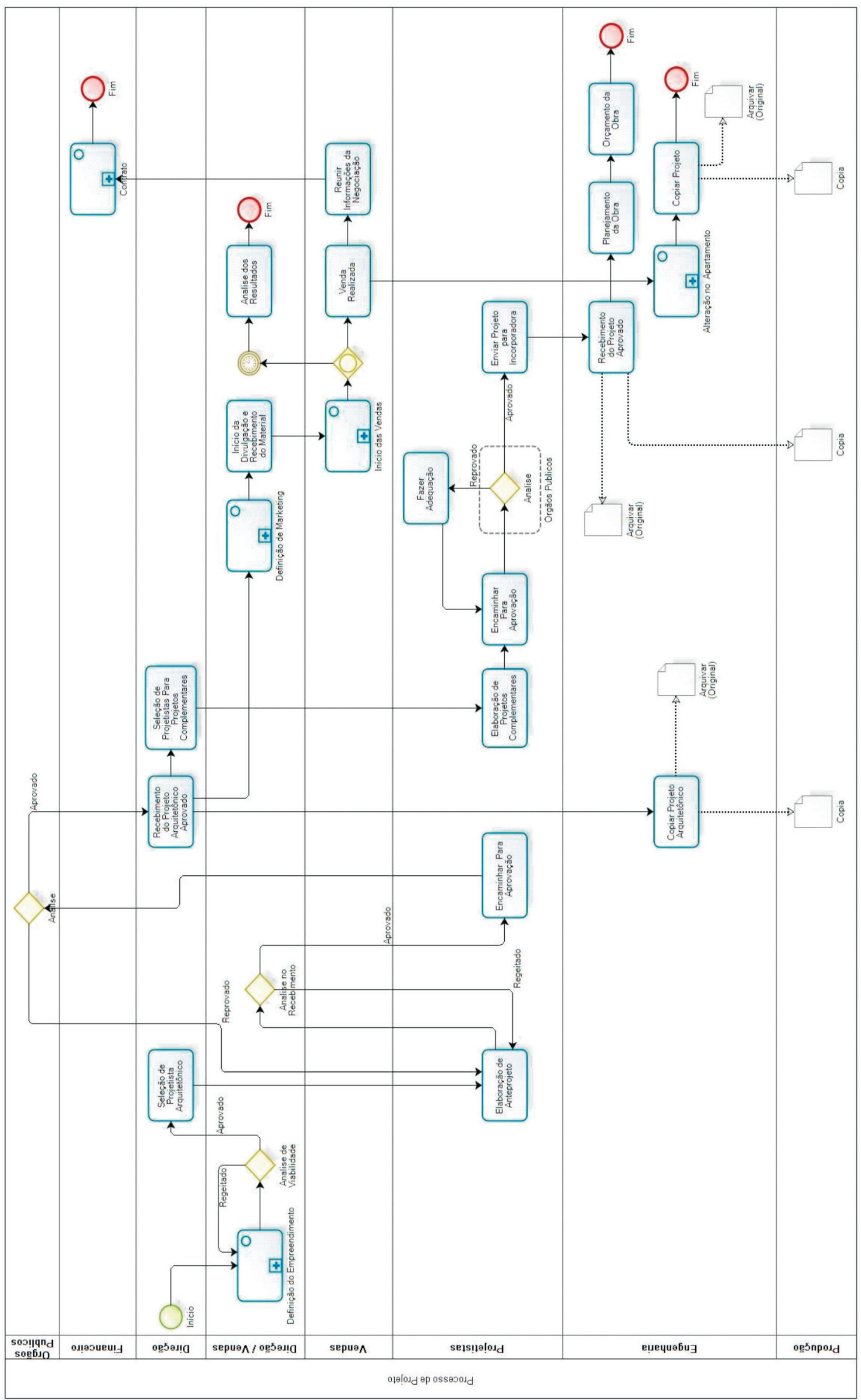

Figura 4 - Processo atual de gestão do projeto do empreendimento (as is) 


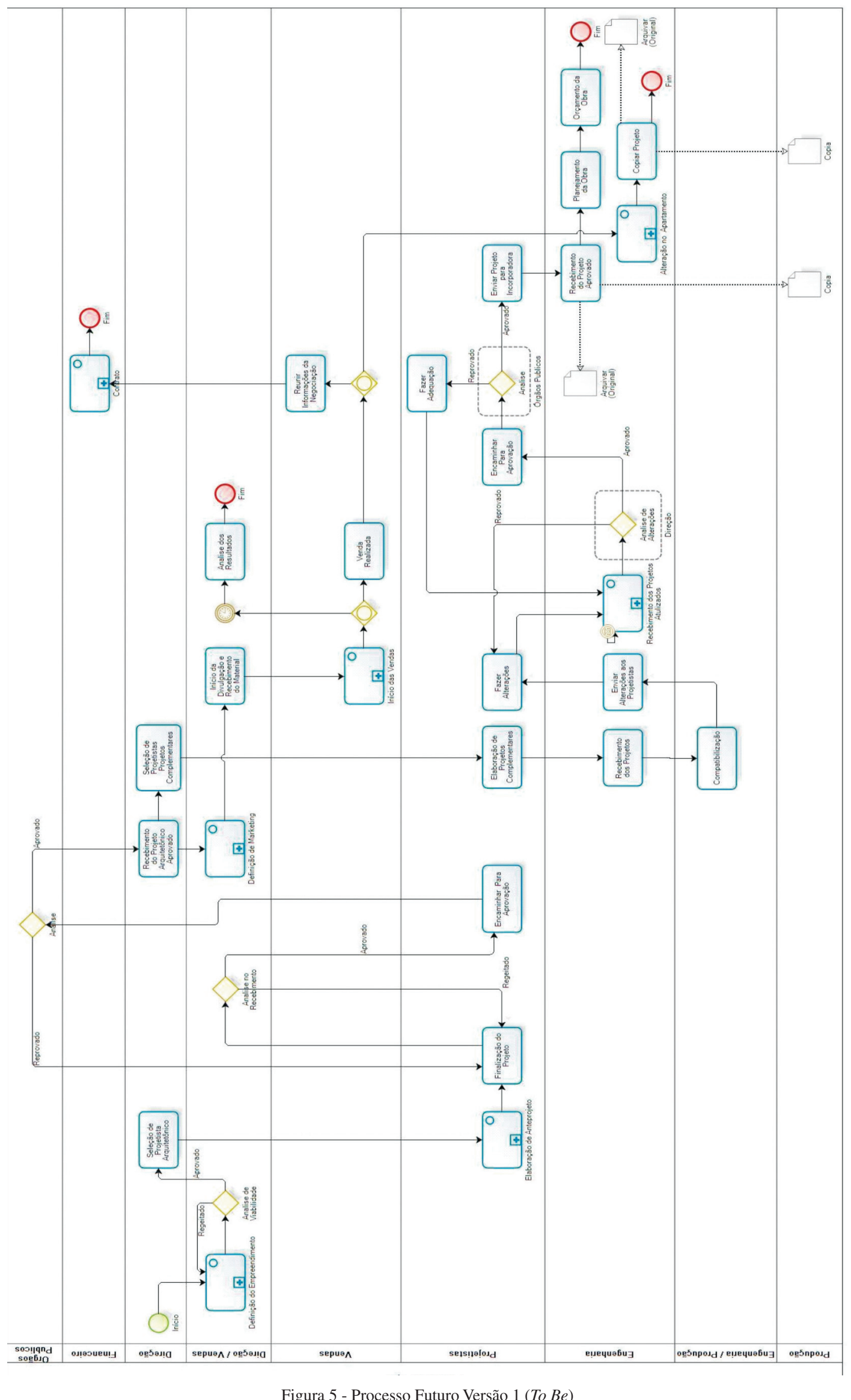

Figura 5 - Processo Futuro Versão 1 (To Be) 


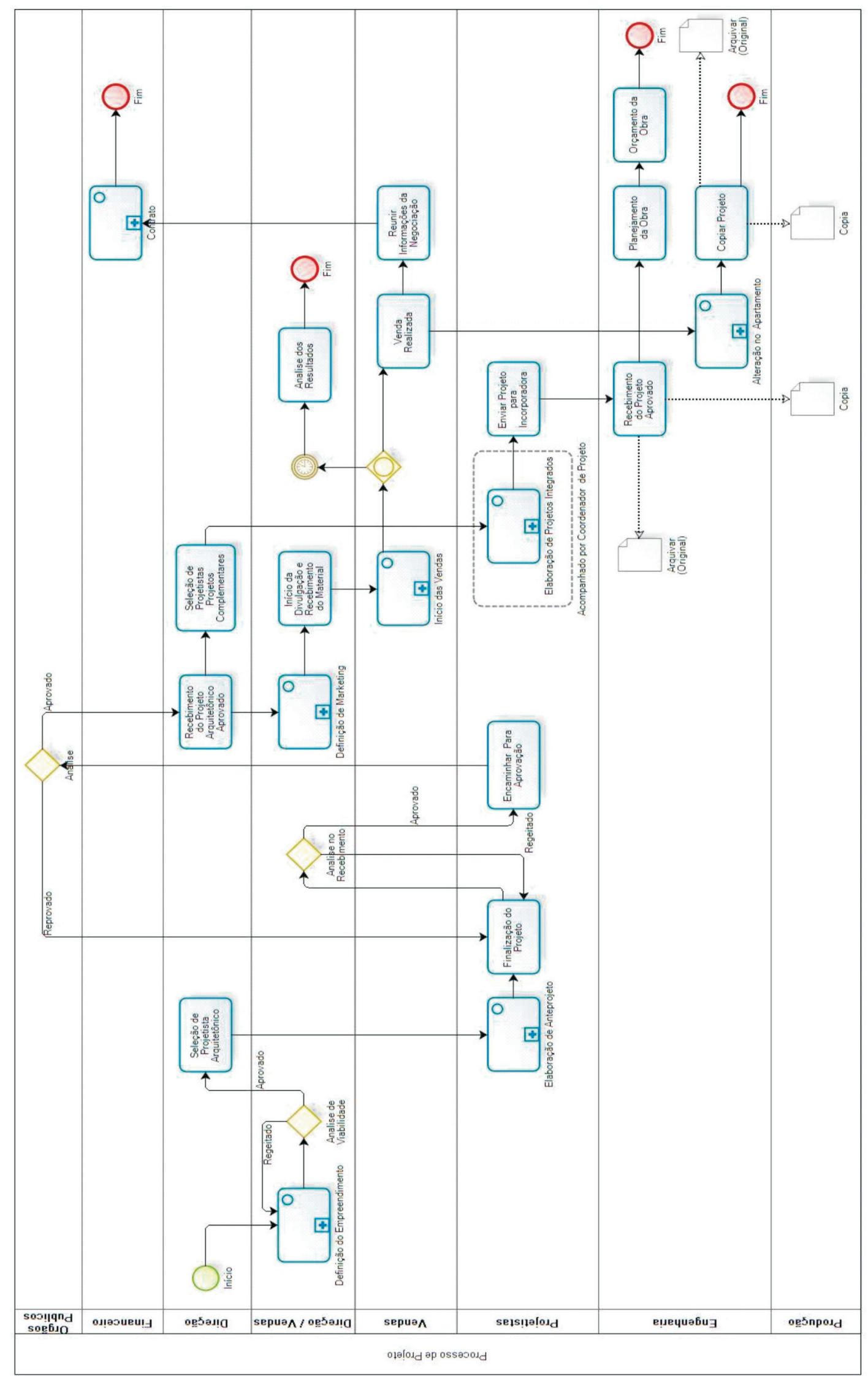

Figura 6 - Processo Futuro Versão 2 (To Be) 


\section{Análise dos Resultados}

Observou-se que a empresa possuía de maneira informal todo o planejamento e a coordenação da gestão do projeto contratado, evidenciando a necessidade de uma melhor apresentação e formalização de todas estas etapas e fases onde estas têm fundamental importância para o gerenciamento do processo. Nota-se ainda a grande importância em se identificar o escopo do processo, pois somente assim é possível chegar a pontos determinantes e adequados para que o processo realmente atenda aos objetivos galgados pela empresa.

\subsection{Análise da modelagem As Is}

Com a modelagem do processo " $a$ s is" torna-se possível identificar cada um dos subprocessos inseridos dentro do macro processo. Para analisá-lo de forma mais completa e crítica, identificando pontos falhos e tarefas que não agregam valor.

Verifica-se que o departamento de engenharia e de produção não tem participação técnica nas análises e atividades de desenvolvimento da execução do projeto. Sendo assim perde-se toda a experiência destes setores no andamento do processo. Experiência esta que pode identificar no projeto grande parte das deficiências e as futuras ocorrências.

Ainda é importante destacar a participação da direção na definição do projeto arquitetônico. Etapa esta que tem caráter cultural dentro da empresa e que integra a direção da empresa para esta atividade.

\subsection{Definição do processo to be}

É importante destacar que as melhorias propostas nas duas versões do processo to be foram somente referentes ao fluxo de projeto, não abrangendo os fluxos dos subprocessos de vendas, marketing e contrato, pois a intenção deste trabalho se detem à melhoria do fluxo referente à gestão do projeto, apesar de diversas etapas estarem vinculadas ao macro processo da gestão do projeto, no âmbito do sucesso do empreendimento.

Nas duas versões apresentadas pode-se observar que foram respeitadas as práticas de caráter cultural da empresa, com o objetivo de que o novo processo seja aceito pela direção sem imposição de um fluxo.

Nota-se que a primeira sugestão de melhoria é o acréscimo de um subprocesso de anteprojeto e somente após este estar concluído sejam realizados os detalhamentos do projeto arquitetônico para que seja liberado para provação perante os órgãos públicos.
Supõe-se que na versão 1 apresentada não serão utilizadas ferramentas de gestão de projetos diferentes da segunda versão em que há o subprocesso de projeto integrado o qual sugere-se que seja executado com o auxilio de um ambiente colaborativo. Assim surge a necessidade da participação do departamento de engenharia e da produção para que seja realizada a compatibilização entres os projetos complementares. Esta etapa, como mostrado anteriormente, tem fundamental importância para que seja atingido o objetivo de redução de custos, correção de erros, incremento da qualidade do projeto e do empreendimento visando a satisfação do cliente.

Nas duas versões foi evidenciada a necessidade de uma maior participação do departamento técnico (engenharia) da empresa, onde esta participação não é visualizada no processo as is, entretanto sua participação tem grande importância na qualidade do projeto final, pois é este agente que faz todo o acompanhamento do projeto na sua execução.

Para a versão 2 é recomendado o subprocesso de elaboração de projetos de forma integrada. Etapa esta que traz um grande benefício no fluxo de atividades e, além disso, é possível observar a grande redução de tarefas, pois este subprocesso abranje todas as tarefas que foram eliminadas ao se relacionar com a primeira versão (pode-se observar a redução de atividades visualmente ao comparar as duas versões).

Na elaboração de projetos integrados, todo o controle e compatibilização são realizados pelos projetistas.

Também é importante evidência que com a elaboração de projetos integrados forma-se uma rede de diversas possibilidades de reajustes no projeto, deixando-os adequados para a análise dos órgãos públicos e a geração de um projeto para a produção.

\section{Conclusão}

Com o objetivo de desenvolver a modelagem da gestão do processo de projeto, em uma incorporadora, buscando identificar pontos críticos, foi possível verificar a aplicabilidade da BPM como técnica de modelagem.

Constitui-se com esta modelagem de processo, uma contribuição para a melhoria continua da gestão no processo de projeto da incorporadora. Salienta-se ainda que este modelo de gestão do processo de projeto foi aplicado levando em consideração a cultura da empresa assim não se garante que o mesmo modelo será eficiente em demais empresas mesmo que sejam do setor de incorporação, porém com as devidas adaptações, o modelo pode ser validado. 
É de grande importância evidenciar o resultado efetivo obtido na apresentação de duas soluções para ser utilizado pela incorporadora.

O que constata-se é a efetivação do uso de uma ferramenta de modelagem para avaliação dos processos vislumbrando a melhoria de produtividade com a implantação de uma das opções apresentadas.

\section{Referências}

AMARAL, T. G. Gerenciamento do ciclo do processo de projeto. In: XI Encontro Nacional de Tecnologia no Ambiente Construído. Florianópolis - SC, 2006, Anais... Associação Nacional de Tecnologia do Ambiente Construído, 2006, 11p.

ASSOCIAÇÃO BRASILEIRA DE NORMAS TÉCNICAS. NBR ISO 9001: Sistemas de gestão da qualidade - Requisitos. Rio de Janeiro, 2000.

BACK, N.; OLIVEIRA, R.; ROMANO F.V. A Importância da modelagem do processo de projeto para o desenvolvimento integrado de edificações, 1998. Disponível em: <http://www.lem.ep.usp.br/gpse/es23/ anais/A_IMPORTANCIA_DA_MODELAGEM_DO_ PROCESSO_DE_PROJETO.pdf $>$ Acesso em: 23 set. 2008.

BALDAM, R. de L. et al. Gerenciamento de processos de negócios: BPM - business process management. 1. ed. São Paulo: Érica 2007. 240p.

BENEDETE, A. C. Roteiro para a definição de uma arquitetura SOA utilizando BPM. Monografia (MBA em Tecnologia da Informação) - Escola Politécnica da Universidade de São Paulo, São Paulo - SP, 2007. 68p.

BENEDICTIS, C. C. et al. Avaliação dos principais métodos e ferramentas disponíveis para a modelagem do processo de desenvolvimento de produto. IV Congresso Brasil de Gestão e Desenvolvimento de Produtos, Gramado - RS, 2003. 10p.
BRAGAGLIA, U. J. Formalização de um sistema de procedimentos para gerenciamento e coordenação de projetos em escritórios de arquitetura. Dissertação (Mestrado em Engenharia Civil) - Universidade Federal de Santa Catarina. Florianópolis - SC, 2006, 192p.

CAVALCANTI, E. X. et al. A Modelagem de Processos de Negócios em empresa publica - A Experiência da Comissão Nacional de Energia Nuclear - CNEN na modelagem dos processos de negócios do Serviço de Tecnologia da Informação - SETIN. Artigo apresentado ao $2^{\circ}$ Congresso Científico da UniverCidade, Rio de Janeiro. 2007, 8p. Disponível em: <http//www.univercidade.edu/uc/pesqcient/pdf/2007/gest_procneg.pdf> Acesso em: 23 set. 2008.

CORADI, C. A Coordenação e o fluxo de informações no processo de projetos de edificações. 2004. 61p. Monografia (Bacharelado em Engenharia Civil) - Universidade Comunitária Regional de Chapecó, Chapecó - SC.

CRUZ, M. G. et al. Modelagem de Processos de Negócios: Metodologia. Universidade Federal da Bahia, 2006. 31p. Salvador - BH. Disponível em: <http/twiki. dcc.ufba.br/pub/Residência/Trabalhos/ResidenciaEmSoftware-MetodologiaDeModelagemDeProcessos. pdf>. Acesso em: 23 set. 2008.

MACEDO S. R.; SCHIMITZ E. A. Ferramentas de modelagem de processos: uma avaliação, 2001. Disponível em: <http/www.triadesolucoes.com.br/Files/ Artigo_001.pdf>. Acesso em: 23 set. 2008.

SILVA M. A. C.; SOUZA R. Gestão do processo de projeto de edificações. 1. ed. São Paulo: O Nome da Rosa, 2003. 181p.

SOUZA A. L. R.; MELHADO S. B. Preparação da Execução de Obras. 1. ed. São Paulo: O Nome da Rosa, 2003. 143 p.

Recebido em: 23/07/2009. Aceito em: 19/07/2011. 